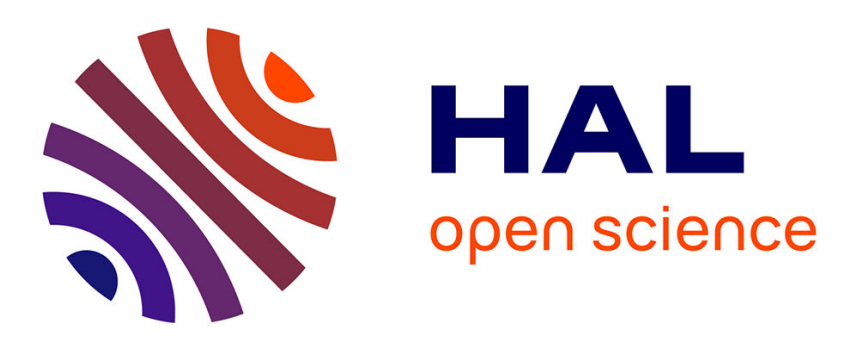

\title{
Contactless conductivity measurement for ITO nanolayers on AsGa substrats over a wide frequency range
}

Florent Loete, Hajer Makhloufi, Yann Le Bihan, Denis Mencaraglia

\section{- To cite this version:}

Florent Loete, Hajer Makhloufi, Yann Le Bihan, Denis Mencaraglia. Contactless conductivity measurement for ITO nanolayers on AsGa substrats over a wide frequency range. IEEE SENSORS 2018, Oct 2018, New delhi, India. 10.1109/icsens.2018.8589554 . hal-01943876

\section{HAL Id: hal-01943876 \\ https://hal-centralesupelec.archives-ouvertes.fr/hal-01943876}

Submitted on 4 Dec 2018

HAL is a multi-disciplinary open access archive for the deposit and dissemination of scientific research documents, whether they are published or not. The documents may come from teaching and research institutions in France or abroad, or from public or private research centers.
L'archive ouverte pluridisciplinaire HAL, est destinée au dépôt et à la diffusion de documents scientifiques de niveau recherche, publiés ou non, émanant des établissements d'enseignement et de recherche français ou étrangers, des laboratoires publics ou privés. 


\title{
Contactless conductivity measurement for ITO nanolayers on AsGa substrats over a wide frequency
}

\section{range}

\author{
Florent Loete, H. Makhloufi, Yann Le Bihan, and Denis Mencaraglia \\ GeePs | Group of electrical engineering - Paris \\ UMR CNRS 8507, CentraleSupelec, Univ Paris-Sud, UPMC Sorbonne Universités \\ Gif-sur-Yvette, France \\ Email : florent.loete@centralesupelec.fr
}

\begin{abstract}
We report on the application of a new contactless method based on eddy currents with a view to characterizing some transport properties of a large range of semiconductors. The innovative approach of this work consists in measuring the impedance of the coil by reflectometry using a broadband multicarrier test signal. The device works well with silicon wafers with a constant conductivity over a wide frequency range. Because of their electrical conductivity and high optical transmittance in the visible and near-IR regions of electromagnetic spectrum, indium tin oxide (ITO) films have motivated great interests in experimental studies and technological applications. The estimation of their electrical conductivity is a key point to develop these devices. On this paper we show that the setup can be used for the frequency characterization of ITO and AsGa nanolayers wich exhibit a frequency dependent behavior. The low frequency measurement are found in agreement with the classical four point probe setup.
\end{abstract}

Keywords- Eddy currents, semiconductors, AsGa, ITO conductivity, reflectometry, coil probe

\section{INTRODUCTION}

The estimation of the conductivity is a key point for the development of new semiconductor materials. This is especially true in the field of photovoltaic applications, where high efficiency solar cells is a major concern. The accurate measurement of the conductivity is a critical issue for assessing the electronic grade of materials under development. This has led over the last decades to the development of contactless sensing methods which are very valuable tools for the fast and non-destructive estimation of the conductivity of semiconductors. However, a major drawback of the existing systems, is that their conductivity measurement range is limited since they rely on measurements at a single frequency. Consequently their service frequency is chosen, for optimal sensitivity, as function of the targeted material and one would need to design specific custom measurement systems for each material of interest. Those systems are therefore not sufficient and there is a strong need for a generic measurement system able to cover a large range of semiconductor materials without modifications. The multi-frequency eddy current system (MFECS) coupled to an electromagnetic model described in previous work [1-2] exhibits a very wide thickness and conductivity measurement range. The eddy currents depend on the conductivity of the inspected semiconductor wafer

Our innovative probing method [1-2] consists in injecting a multicarrier signal down a transmission line ended by a coil and measuring the reflected signal created by the line - coil impedance mismatch (Fig. 1).

Although this method can be used for the characterization of a large range of semiconductor wafers without any customization it was so far only tested with a set of doped silicon wafers covering the classical conductivity range of silicon wafer.

Because of their electrical conductivity and high optical transmittance in the visible and near-IR regions of electromagnetic spectrum, indium tin oxide (ITO) films have motivated great interests in experimental studies and technological applications. The exceptional properties of ITO films can be exploited in several applications in optoelectronic devices like solar cells, image sensors and solar collectors. The estimation of their electrical conductivity is a key point to develop these devices. In this work, we investigate the conductivity of ITO films deposited on different substrates. For that purpose, our innovative contactless conductivity measurement system based on eddy currents has been used. The experimental results presented are intended to demonstrate the capacity of our developed system to characterize in frequency different materials other than silicon

\section{EXPERIMENTAL SETUP}

\section{A. Eddy current testing system}

Our innovative probing method [1-2] consists in injecting a multicarrier signal down a transmission line ended by a coil and measuring the reflected signal created by the line - coil impedance mismatch (Fig. 1).

It follows that the signal reflected at the coil impedance mismatch depends on the semiconductor sample properties. Fig. 2 shows the characterization of a sample with constant conductivity over frequency. The conductivity of the sample is computed using a model based approach. The fast electronic 
setup developed in this work, composed of a FPGA card, high speed DAC and ADC, allowed the construction of a signal over the $[10 \mathrm{MHz}-1 \mathrm{GHz}]$ frequency range, resulting in a up to 5 ns conductivity sampling capability.

This method can be used for the characterization of a large range of semiconductor wafers without any customization. This can be a major advantage for the fast development and optimization of various new semiconductor materials. The device is also very fast and can therefore be a very powerful tool for the fast quality assessment of the wafers in a production line.

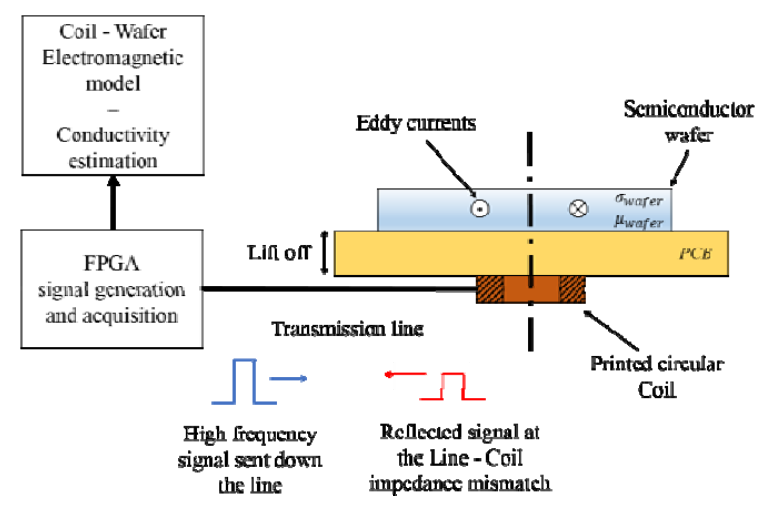

Fig. 1. Setup of the MFECS device. A multicarrier signal is sent and reflected at the coil-line impedance mismatch resulting in a multifrequency determination of the coil impedance. The conductivity of the wafer is then estimated by using an electromagnetic model.

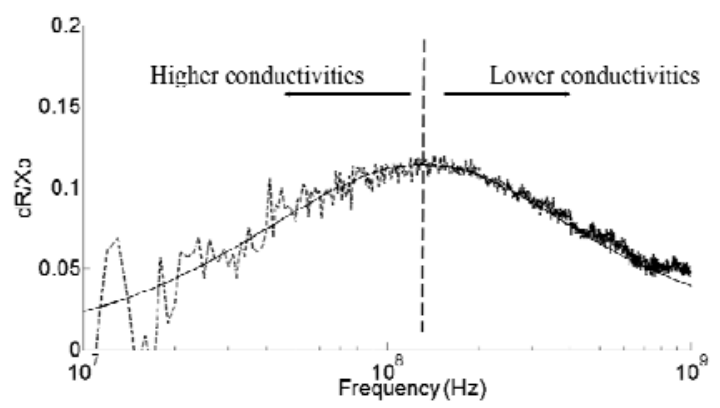

Fig. 2. Comparison of the experimental $(--)$ and fitted (-) normalized resistance variation of the coil in presence of a semiconductor sample, as a function of frequency.

As explained previously, this setup was already tested with silicon wafers with an almost constant conductivity over the $[10 \mathrm{MHz}-1 \mathrm{GHz}]$. In his work the model based estimation was modified in order to achieve conductivity estimation at each frequency of the spectrum.

\section{B. ITO and AsGa samples}

ITO films were deposited using RF magnetron sputtering system (Plassys MP 800) in a pure argon atmosphere using a
99.98\% In2O3: $\mathrm{SnO} 2(90: 10), 6$ in. target. The system base pressure was $(1 \times 10-6$ Torr $)$. The sample holder is designed to support 4 in. silicon wafers and the rotation of the sample holder is maintained at $6 \mathrm{rpm}$ for all depositions. $\mathrm{HCl}$ etched GaAs wafers ( $\left.\begin{array}{lll}1 & 0 & 0\end{array}\right)$, p-type, $\mathrm{Zn}$ doped, $2 \times 10^{18}-5 \times 10^{19} \mathrm{~cm}^{-3}$ have been used as substrates. Depositions were carried for about 10 min to deposit 200-nm thick ITO layers. An argon partial pressure of $0.04 \mathrm{~Pa}$ and a power density of $200 \mathrm{~W}, 2.5$ $\mathrm{W} / \mathrm{cm} 2$ were used during the depositions. All of the samples were prepared using the same sputtering parameters followed by annealing at $400^{\circ} \mathrm{C}$ for $1 \mathrm{~h}$ in $\mathrm{N} 2$. The thickness of the ITO films was measured using a DEKTAK stylus profilometer. Current-voltage (I-V) measurements were performed for ITO/p-GaAs heterostructures at (RT) using a (Keithley 617 electrometer).

The frequency measurements of the deposited ITO layer with our system are showed in Fig 3.

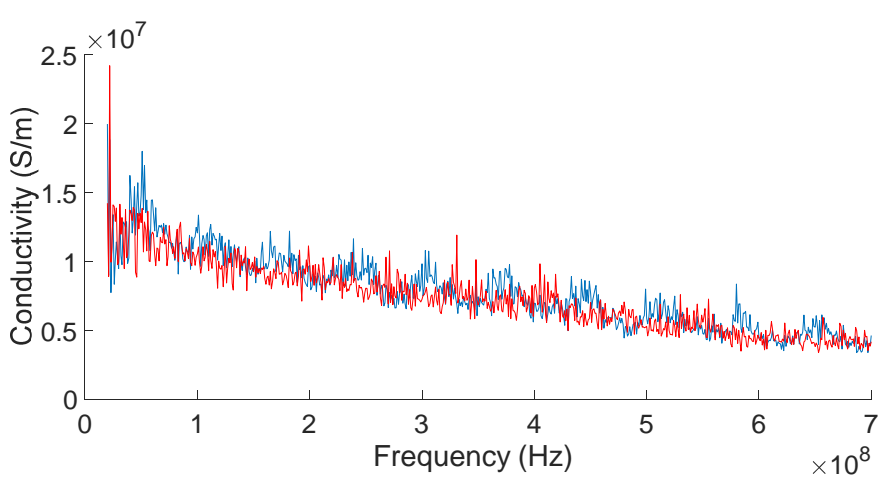

Fig. 3. Conductivity of $200 \mathrm{~nm}$ and $500 \mathrm{~nm}$ ITO layer on $350 \mu \mathrm{m}$ AsGa substrat

The results presented in Fig 3 where correlated at low frequency with a classical four points probe measurement. It also shows the ability of the MFECS to characterize any type of conducting layer over a wide frequency range thus opening the possibility of a wide range of applications.

\section{CONCLUSION}

The wideband eddy current method (MFECS) designed for the measurement of the conductivity of a large range of semiconductor wafers was validated for the measurement of ITO nanolayers on AsGa substrat. Further investigations and enhancements are ongoing to validate the device on other materials and over a wider frequency range.

\section{REFERENCES}

[1] F. Loete, Y. Le Bihan and D. Mencaraglia, FR patent FR 1553392 (16 April 2015)

[2] F. Loete, Y. Le Bihan and D. Mencaraglia, "Novel Wideband Eddy Current Device for the Conductivity Measurement of Semiconductors", IEEE sensors journal, vol.16, no. 11, pp. 4151 - 4152, (2016 